\title{
Post-partum hypoglycaemia in lactating women with type 1 diabetes: a pilot study using continuous glucose monitoring
}

\author{
BERIT INKSTER, ${ }^{1}$ JACQUI ELDER, ${ }^{2}$ CLAIRE ALEXANDER, ${ }^{2}$ LOUISE OSBORNE, ${ }^{3}$ \\ NICOLA N ZAMMITT, ${ }^{1}$ BRIAN M FRIER ${ }^{1}$
}

\begin{abstract}
Aims: To observe glucose profiles in post-partum women with type 1 diabetes with a particular focus on hypoglycaemia.

Methods: Post-partum women with type 1 diabetes were studied for 4 weeks using home blood glucose monitoring (HBGM) and continuous glucose monitoring (CGM). Episodes of hypoglycaemia were documented using self-reported questionnaires.

Results: Of 15 consenting participants, only six women completed the study, four of whom breastfed their baby. HBGM was performed a median of 7 times per day. No severe hypoglycaemia (requiring third party assistance) occurred, but a median of 17 (range 10-23) episodes of mild hypoglycaemia occurred. In all participants, CGM revealed several episodes of hypoglycaemia that were not detected by capillary blood glucose testing.

Conclusions: Asymptomatic hypoglycaemia is common during breastfeeding. Recruitment and retention difficulties illustrate the challenge of studying glycaemia and intensive interventions in the post-partum period. Education programmes may help to reduce post-partum hypoglycaemia in women with type 1 diabetes.

Br J Diabetes Vasc Dis 2015;15:119-122
\end{abstract}

Key words: continuous glucose monitoring, hypoglycaemia, post partum, type 1 diabetes, lactation

\section{Introduction}

Strict glycaemic control is recommended for mothers with diabetes before conception and during pregnancy to reduce the risk

Department of Diabetes, Royal Infirmary of Edinburgh, Scotland, UK Simpson Centre for Reproductive Health, Royal Infirmary of Edinburgh, Scotland, UK

Diabetes Centre, Victoria Hospital, Kirkcaldy, Scotland, UK

Address for correspondence: Dr Berit Inkster Department of Diabetes, Royal Infirmary of Edinburgh, 51 Little France Crescent, Edinburgh EH16 4SA, Scotland, UK

Tel: +44 (0)1312421466

Fax: +44 (0)1312421485

E-mail: berit.inkster@luht.scot.nhs.uk

http://dx.doi.org/10.15277/bjdvd.2015.026 of foetal complications. ${ }^{1}$ Strict glycaemic control after childbirth results in normal breast milk composition, but this may increase the risk of hypoglycaemia and this approach is often not emphasised in practice. ${ }^{1-3}$ Barriers to optimal self-management include a fall in insulin requirement following delivery, maintenance of a regular diet and the need for frequent home blood glucose monitoring (HBGM) while caring for a neonate. Unfortunately, little evidence is available on which to base advice on insulin dosage for these patients. . $^{3-7}$ Unsurprisingly, qualitative evidence suggests that many women with type 1 diabetes find post-partum selfmanagement to be challenging, to which fear of hypoglycaemia may contribute. ${ }^{8,9}$

The aim of the present study was to monitor glycaemic control in women with type 1 diabetes for 4 weeks post-partum, with a particular focus on the frequency of hypoglycaemia.

\section{Patients and methods}

This was a short-term, observational study of a small number of post-partum women with type 1 diabetes, in order to assess the feasibility of carrying out a larger trial. Ethical approval for the study was obtained from the local medical ethics research committee and all participants gave written, informed consent.

A continuous glucose monitoring (CGM) device (iPro2 with Sof-sensor, Medtronic MiniMed, Northridge, USA) was applied within 1 week of delivery. The study commenced on the first day of CGM monitoring and continued for 4 weeks, with participants wearing the CGM device for the first and last 6 days. They were asked to measure capillary blood glucose at least four times daily and to record each experience of biochemical or symptomatic hypoglycaemia (blood glucose $<3 \mathrm{mmol} / \mathrm{L}$ or symptoms of hypoglycaemia) in a questionnaire. The first CGM device was fitted before they left the hospital, and the second was fitted at each participant's house by one of the investigators (BI). A stamped, addressed, padded envelope was provided for return of the sensors. These measures ensured that no additional visits to hospital were required.

Two doctors (BI and NNZ) analysed the CGM recordings independently. The total amount of valid CGM data was determined for each recording, and periods of low interstitial glucose classified into $<3.0 \mathrm{mmol} / \mathrm{L}$ (LIG3) and $\leq 2.2 \mathrm{mmol} / \mathrm{L}$ (LIG2.2; note that LIG3 included all recordings of $<3.0 \mathrm{mmol} / \mathrm{L}$, including episodes of LIG2.2). A documented episode of hypoglycaemia 
Table 1. Patient characteristics

\begin{tabular}{|c|c|c|c|c|c|c|}
\hline Participant & $\begin{array}{l}\text { Age } \\
(y)\end{array}$ & $\begin{array}{l}\mathrm{HbA}_{1 \mathrm{c}} \\
(\mathrm{mmol} / \\
\mathrm{mol})\end{array}$ & CSII? & $\begin{array}{l}\text { Diabetes } \\
\text { duration } \\
\text { (y) }\end{array}$ & $\begin{array}{l}\text { Gold } \\
\text { score }\end{array}$ & $\begin{array}{l}\text { Feeding } \\
\text { method }\end{array}$ \\
\hline O2E & 39 & 70 & No & 3 & 1 & breast \\
\hline O3E & 26 & 91 & No & 13 & 2 & bottle \\
\hline $08 \mathrm{E}$ & 34 & 55 & No & 23 & 3 & breast \\
\hline $11 \mathrm{E}$ & 38 & 57 & Yes & 16 & 1 & mixture \\
\hline $01 \mathrm{~F}$ & 35 & 53 & Yes & 30 & 4 & breast \\
\hline $02 \mathrm{~F}$ & 30 & 56 & Yes & 12 & 1 & breast \\
\hline
\end{tabular}

had to have persisted for at least 20 minutes, and was considered complete when the glucose remained above the respective threshold for a further 20 minutes. This method has been used successfully in previous studies. ${ }^{10}$

Data are presented as mean (range) or median (range), except where indicated.

\section{Results}

\section{Study participants}

Of 32 eligible participants, only 15 consented to participate, and nine withdrew consent following delivery. The six remaining participants who completed the study had a median age of 35 (26-39) years and median duration of diabetes of $16(3-30)$ years (Table 1). Median $\mathrm{HbA} 1 \mathrm{c}$ before pregnancy was 56 (46-91) $\mathrm{mmol} / \mathrm{mol}(7.3 \%$ [6.4-10.5\%]). One subject had impaired awareness of hypoglycaemia as defined by a Gold score ${ }^{11}$ of 4; median Gold score was 2. Five women intended to breastfeed, but only four breastfed exclusively throughout the study period.

\section{Insulin doses}

All participants increased their basal insulin during the third trimester compared with pre-pregnancy values, from a median dose of 14 (0-42) units/24 h to 23 (11-62) units/24 h (Figure 1). Overall, there was a reduction in the dose of basal insulin during the first week post-partum (median 14 (9-15) units/24 h; by week 4 the median dose had declined further to $12(6-28)$ units/24 h (Figure 1). One mother did not regularly take basal insulin prior to pregnancy, and managed her diabetes with regular, large doses of a rapid acting insulin analogue, with subsequent poor control $\left(\mathrm{HbA}_{1 \mathrm{c}}\right.$ $91 \mathrm{mmol} / \mathrm{mol}$ [10.5\%]). Another mother on continuous subcutaneous insulin infusion did not provide a pre-pregnancy basal dose, so a comparison could not be made with the post-partum period.

\section{Blood glucose diaries and hypoglycaemia questionnaires}

The average number of blood glucose readings per participant was 3.4-8.8/day (Table 2), reaching as high as 11 readings/day during the first study week. Mean blood glucose values for each mother were $5.3-8.6 \mathrm{mmol} / \mathrm{L}$, with corresponding median values of 5.4-7.5 mmol/L. Low blood glucose levels occurred frequently, with as many as nine episodes $<3.0 \mathrm{mmol} / \mathrm{L}$ occurring within a single week (4-21 episodes occurred over 4 weeks; Table 2). The median frequency of values $<3.0 \mathrm{mmol} / \mathrm{L}$ in week 1 , weeks $2-3$ and week 4 was $2(0-7), 2.7(2.6-5)$ and $2.1(2-9)$, respectively. One woman
Figure 1. Basal insulin doses from pre-pregnancy to end of study period

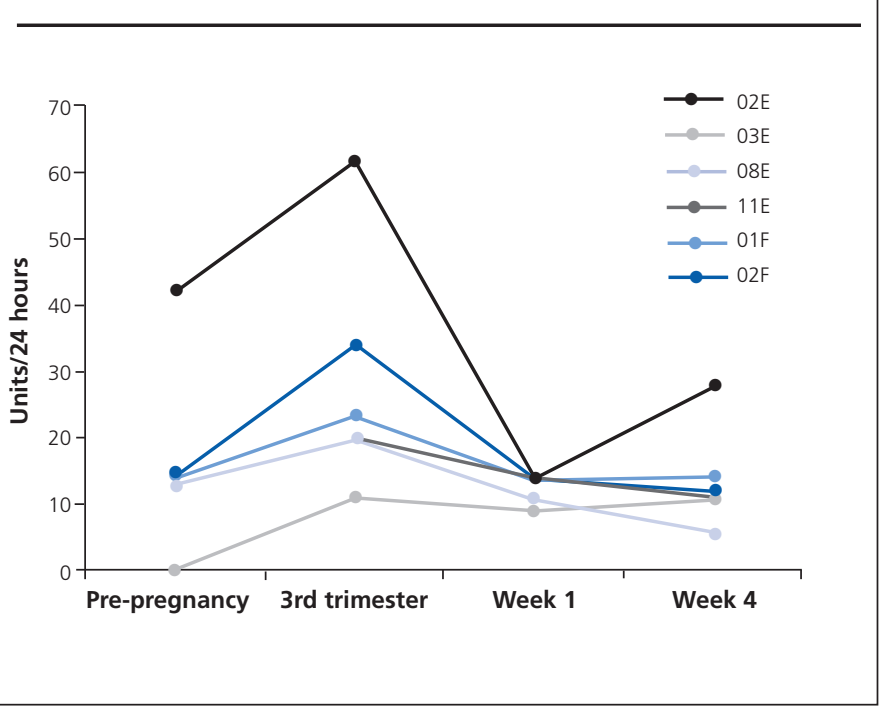

Table 2. Home blood glucose monitoring (HBGM) results over 4 weeks

\begin{tabular}{llllll}
\hline Participant & $\begin{array}{l}\text { Readings } \\
\text { per day }\end{array}$ & $\begin{array}{l}\text { Capillary glucose } \\
\text { (mmol/L) }\end{array}$ & $\begin{array}{l}\text { No. of } \\
\text { readings } \\
<3 \text { mmol/L } \\
\text { Median }\end{array}$ & $\begin{array}{l}\text { No. of } \\
\text { hypo } \\
\text { questionnaires } \\
\text { returned }\end{array}$ \\
\hline O2E & 3.4 & 7.5 & $2.6-19.2$ & $4^{*}$ & $0^{*}$ \\
O3E & 6.8 & 7.2 & $2.1-30$ & 14 & 23 \\
08E & 8.7 & 5.4 & $1.8-18.7$ & 21 & 17 \\
11E & 8.8 & 6.5 & $2.3-13.6$ & 9 & 10 \\
O1F & 6.5 & 5.4 & $2.1-18.1$ & 9 & 10 \\
O2F & 7.3 & 6.2 & $1.9-18.2$ & 12 & 20 \\
\hline
\end{tabular}

*This participant only completed a HBGM diary for weeks 1 and 4

did not complete HBGM during the second and third week of the study.

Each participant submitted between 10 and 23 hypoglycaemia questionnaires (median of 17 overall, excluding one participant who did not complete any hypoglycaemia questionnaires due to pressure of time). The median number per week was 3.8 $(0-10)$ questionnaires in a 1 week period. No episodes of severe hypoglycaemia (requiring third party assistance) occurred, but a median of $3(1-4)$ episodes of hypoglycaemia per woman were unrecognised before routine testing or prompting by a third party. A median of 2 (1-6) events occurred during breastfeeding, and a further $3(1-8)$ events occurred within 1 hour of breastfeeding. Blood glucose values recorded in the hypoglycaemia questionnaires (Table 1) ranged from 1.8-4.3 mmol/L (median $3.0 \mathrm{mmol} / \mathrm{L})$.

\section{CGM analysis}

The first week of CGM (Table 3) was successful for all but one participant, who provided only $3.3 \mathrm{~h}$ of data. The other five achieved a median of 132 (118.8-167.4) h of recording. The five successful 
Table 3. Continuous glucose monitoring results for week 1

\begin{tabular}{llll}
\hline Participant & $\begin{array}{l}\text { Hours } \\
\text { recorded }\end{array}$ & $\begin{array}{l}\text { No. of LIG3.0 } \\
\text { events }\end{array}$ & $\begin{array}{l}\text { No. of LIG2.2 } \\
\text { events }\end{array}$ \\
\hline O2E & 118.8 & 2 & 2 \\
O3E & 143.4 & 9 & 8 \\
O8E & 131.2 & 8 & 2 \\
$11 \mathrm{E}$ & 132.8 & 1 & 0 \\
O1F & 167.4 & 6 & 0 \\
O2F & 3.3 & 0 & 0 \\
\hline
\end{tabular}

LIG3.0/2.2 events: instances of CGM glucose $3.0 \mathrm{mmol} / \mathrm{L}$ or $<2.2 \mathrm{mmol} / \mathrm{L}$, respectively.

Figure 2. Example of a period of CGM monitoring in subject O3E during the first week of the study. Blue flags indicate when breast-feeding took place; black circles indicate home blood glucose measurement calibration; the grey bar shows a range of blood glucose between 3.9 and $7.8 \mathrm{mmol} / \mathrm{L}$

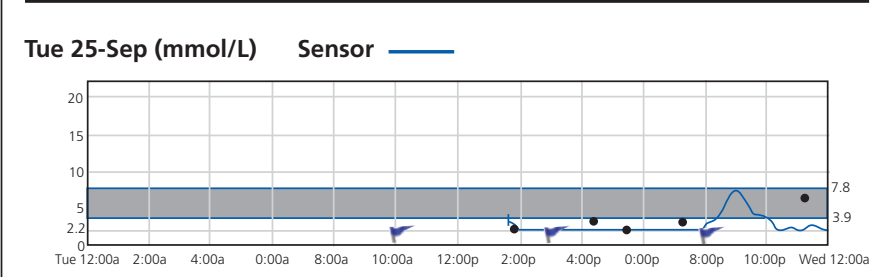

Wed 26-Sep (mmol/L) Sensor

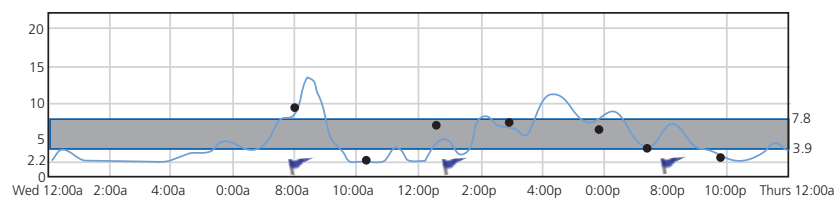

Thu 27-Sep (mmol/L) Sensor

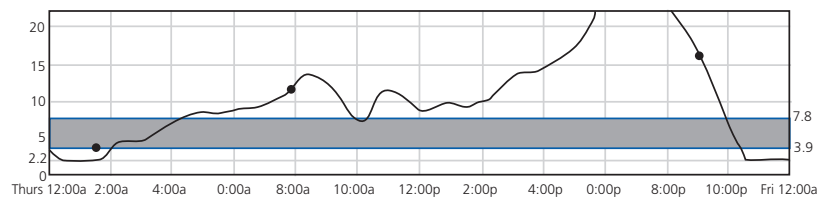

traces showed a median of 4 (1-9) episodes of LIG3.0. The median time spent with glucose $<3.0 \mathrm{mmol} / \mathrm{L}$ was $2.61(0.5-21.2) \mathrm{h}$, accounting for $0.38-14.8 \%$ of total CGM time. LIG2.2 was less common, with a median of $1(0-8)$ episode per woman. The time spent in LIG2.2 was 0.34 (0-15) h. A median of 4 (1-6) episodes of hypoglycaemia on CGM were not identified by HBGM. About half of the LIG2.2 events were not identified by HBGM (8/15 events). Figure 2 shows an example of a CGM trace.

CGM recording was successful in only one participant during the final 6 days, for $136 \mathrm{~h}$, due to a high rate of sensor failure. This woman had eight episodes of LIG 3.0, over a total of $12.7 \mathrm{~h}$ (9.3\% of recording time). Three of these episodes were LIG2.2, for a total of $4.2 \mathrm{~h}$ ( $3 \%$ of recording time). Five episodes of hypoglycaemia were undetected by routine blood glucose monitoring.

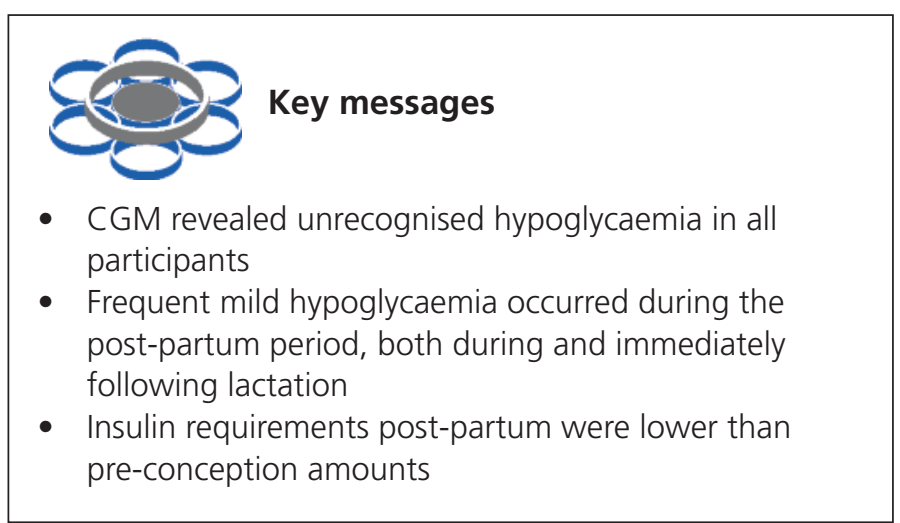

\section{Discussion}

Recruitment and retention of post-partum mothers was extremely difficult despite the study requiring little additional commitment beyond the usual level of care. This may reflect the stressful and demanding nature of the post-partum period for new mothers with type 1 diabetes. Those who were recruited may represent a highly motivated subgroup, demonstrated by their performance of a median of $>7$ blood glucose readings per day. However, recruitment failure highlights the problems of trying to optimise post-partum diabetes care, as many mothers were unwilling or unable to attend additional clinical review, or to use CGM while coping with the demands of motherhood. Previous studies of pregnant mothers with type 1 diabetes have also failed to recruit a substantial number of participants, and have reported high drop-out rates postpartum. 4,7,12 The performance of meaningful studies may require multi-centre collaboration to recruit a sufficient number of pregnant mothers, and study protocols carefully designed to maximise ease of participation by avoiding additional hospital visits and allowing flexibility of timing.

CGM proved to be unreliable in the present study, with $6 / 12$ traces yielding $<25 \mathrm{~h}$ of data. The reason for this is unclear, although there may have been a problem with one particular batch of sensors. All but one failure occurred in the fourth week post-partum, raising the possibly that the subcutaneous tissue around the abdomen at this time may be unsuitable for CGM. The sensors were all fitted by the same investigator (BI) who was trained in this technique, which would minimise the potential for intra-operator variability. The successful periods of monitoring were useful to identify unrecognised hypoglycaemia in all participants, over and above hypoglycaemia demonstrated by frequent HBGM. Hypoglycaemia occurred more often than is observed in a typical non-pregnant adult with type 1 diabetes (an average of 2 episodes per week ${ }^{13,14}$ ). Periods of hypoglycaemia were very prolonged in some subjects, and occurred during periods of breastfeeding; the potential for cognitive impairment and progression to severe hypoglycaemia could put the infant at risk. ${ }^{9}$

In the present study, interpreting (and predicting) insulin dosage was difficult with such a small number of participants. Overall, mothers reduced their basal insulin dose to below prepregnancy values by week 4 post-partum, consistent with previous observations. ${ }^{7}$ It may be appropriate to modify current advice 
and suggest that post-partum, mothers should reduce their insulin doses to below pre-pregnancy values to avoid developing prolonged hypoglycaemia. Dietary advice regarding increased carbohydrate intake and use of low glycaemic index carbohydrate would also be appropriate.

Conflict of interest The authors declare no conflicts of interest. Funding This study did not receive any external financial support.

Acknowledgments The study protocol was developed by BI, JE, CA, NNZ and BMF. Recruitment was performed by BI and LO. Data analysis was performed by BI and NNZ. The manuscript was drafted by BI and all authors contributed to and agreed the final version. Bl is the guarantor and takes responsibility for the contents of the article. The results were presented in poster form at the Scottish Society of Physicians annual meeting 2013.

\section{References}

1. Taylor R, Davidson JM. Type 1 diabetes and pregnancy. BMJ 2007;334:742-5. http://dx.doi.org/10.1136/bmj.39154.700417.BE

2. Van Beusekom CM, Zeegers TA, Martini IA, et al. Milk of patients with tightly controlled insulin-dependent diabetes mellitus has normal macronutrient and fatty acid composition. Am J Clin Nutr 1993;57:938-43.

3. Achong N, Duncan EL, McIntyre D, Callaway L. Peripartum management of glycemia in women with type 1 diabetes. Diabetes Care 2014;37:36471. http://dx.doi.org/10.2337/dc13-1348

4. Riviello C, Mello G, Jovanovic LG. Breastfeeding and the basal insulin requirement in type 1 diabetic women. Endocr Pract 2009;15:187-93. http://dx.doi.org/10.4158/EP.15.3.187

5. Soltani H, Dickinson FM, Kalk J, Payne K. Breast feeding practices and views among diabetic women: a retrospective cohort study. Midwifery
2008;24:471-9. http://dx.doi.org/10.1016/j.midw.2007.04.005

6. Stage E, Norgard H, Damm P, Mathiesen E. Long-term breast-feeding in women with type 1 diabetes. Diabetes Care 2006;29:771-4. http://dx.doi.org/10.2337/diacare.29.04.06.dc05-1103

7. Saez-de-lbarra L, Gaspar R, Obesso A, Herranz L. Glycaemic behaviour during lactation: Postpartum practical guidelines for women with type I diabetes. Pract Diabet Int 2003;20:271-5.

http://dx.doi.org/10.1002/pdi.529

8. Gagne MP, Leff EW, Jefferis SC. The breast-feeding experience of women with type 1 diabetes. Health Care Women Int 1992;13:249-60. http://dx.doi.org/10.1080/07399339209516000

9. Sparud-Lundin C, Berg M. Extraordinary exposed in early motherhooda qualitative study exploring experiences of mothers with type 1 diabetes. BMC Women's Health 2011;11:10. http://dx.doi.org/10.1186/1472-6874-11-10

10. UK Hypoglycaemia Study Group. Risk of hypoglycaemia in types 1 and 2 diabetes: effects of treatment modalities and their duration. Diabetologia 2007;50:1140-7. http://dx.doi.org/10.1007/s00125-007-0599-y

11. Gold A, MacLeod KM. Frequency of severe hypoglycaemia in patients with type 1 diabetes with impaired awareness of hypoglycaemia. Diabetes Care 1994:17:697-703. http://dx.doi.org/10.2337/diacare.17.7.697

12. Murtaugh MA, Ferris AM, Capacchione CM, Reece EA. Energy intake and glycemia in lactating women with type 1 diabetes. J Am Diet Assoc 1998;98:642-8. http://dx.doi.org/10.1016/S0002-8223(98)00147-3

13. Pedersen-Bjergaard U, Pramming S, Heller SR, et al. Severe hypoglycaemia in 1076 adult patients with type 1 diabetes: influence of risk markers and selection. Diabetes Metab Res 2004;20:479-86. http://dx.doi.org/10.1002/dmrr.482

14. Pramming S, Thorsteinsson B, Bendtson I, Binder C. Symptomatic hypoglycaemia in 411 type 1 diabetic patients. Diabetic Med 1991;8:217-22. http://dx.doi.org/10.1111/j.1464-5491.1991.tb01575.x

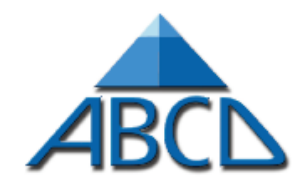

Association of British Clinical Diabetologist

\section{Canagliflozin (Invokana) Nationwide Audit Launching Soon!}

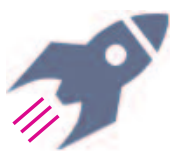

$A B C D$ is about to launch a nationwide audit of canagliflozin in the UK

to assess real clinical efficacy and safety \& inform future practice and guidelines

\section{Does your centre use canagliflozin (Invokana)?}

If yes, REGISTER YOUR CENTRE:

at http://www.diabetologists-abcd.org.uk/n3/Canagliflozin_Audit.htm

- you are invited to enter your patients' data into the bespoke online tool

- you will be able to analyse your local data easily

- the data will be automatically added to the national data in anonymised form

- we can provide easy-to-complete paper proformas for use in clinic if preferred

\section{Please remember:}

- the more data, the more complete our understanding of of canagliflozin in real clinical practice - all contributors will be listed in publications arising from data submission 